\title{
Importancia de las resistencias antibióticas bacterianas en dermatología
}

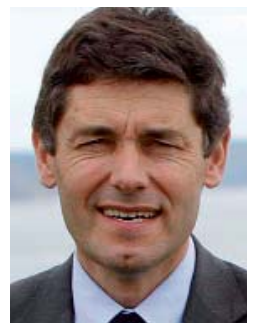

José M. Eiros Bouza Microbiología. Hospital Clínico Universitario de Valladolid. Vicedecano.

Facultad de Medicina. Universidad de Valladolid.

\section{INTRODUCCIÓN}

Para abordar conceptualmente el tema de las resistencias bacterianas en el ámbito profesional del dermatólogo asistencial, efectuaremos una exposición estructurada en cuatro apartados: marco conceptual, métodos de detección, estado actual y posibilidades de actuación. Todo ello con una visión eminentemente aplicada al ejercicio diario en los sistemas sanitarios de nuestro país.

\section{MARCO CONCEPTUAL}

Está bien documentado que la aparición de los antibióticos en medicina motivó una reflexión importante acerca de la próxima finalización del impacto de las enfermedades infecciosas bacterianas. A lo largo de las últimas cinco décadas, se han desarrollado cerca de una treintena de familias de quimioterápicos y antibióticos, con la finalidad de combatir el impacto de la infección comunitaria y nosocomial. En el momento actual, las infecciones bacterianas continúan siendo un gran reto sanitario y, lejos de estar controladas, generan una gran demanda asistencial ${ }^{1}$.

La capacidad bacteriana de desarrollar estrategias de supervivencia se asienta fundamentalmente en dos pilares. En primer lugar, los microorganismos responden a la presión antimicrobiana con nuevos mecanismos de resistencia y, en segundo lugar, adoptan modificaciones estructurales o funcionales de los ya existentes. Por ello, la resistencia antibiótica en bacterias patógenas humanas ha sido considerada por organismos internacionales, como la Organización Mundial de la Salud y los Centers for Disease Control and Prevention (CDC, Atlanta, Georgia, EE.UU.), como un problema clínico, epidemiológico y de salud pública emergente. De manera concomitante, existen iniciativas que, desde el ámbito privado, han impulsado redes de vigilancia de la sensibilidad a los antimicrobianos bajo la tutela de las compañías farmacéuticas y de otras entidades, en aras de colaborar con las redes públicas. Mención especial merece en este contexto la campaña de prevención impulsada por la División de Promoción de la Calidad de la Atención en Salud de los CDC, que ha supuesto un hito educativo y de difusión de buenas prácticas en este ámbito en EE.UU.2. En Europa, el grupo multicéntrico liderado por Cornaglia et al. ${ }^{3}$ ha definido el papel que la investigación básica ha desempeñado en el estudio de mecanismos moleculares y su relación con variables externas que influyen en los mismos y que oscilan entre aspectos tan aparentemente distantes como son las estrategias vacunales y el consumo de probióticos. Lejos de constituir un marco de competencias exclu- 
sivamente médico, este tema engloba aspectos multidisciplinares, en los que la sanidad veterinaria y medioambiental tiene un papel relevante.

Básicamente, la generación de resistencia a los antimicrobianos se establece de acuerdo con dos criterios $^{4}$, que se resumen en la tabla 1 . El primero se denomina con el término de resistencia natural o intrínseca y alude a la imposibilidad estructural de que un antimicrobiano actúe sobre un elemento constitutivo de una bacteria porque ésta carezca de diana para aquél. El segundo se denomina con el término de resistencia adquirida y engloba, por una parte, las modificaciones puntuales en la información genética del tipo de «mutaciones puntuales»y, por otra parte, otras modificaciones más amplias que se asimilan al término de «cromosómicas». Entre éstas, cabe a su vez diferenciar en función de su posición la modalidad de transposones o integrones que, de acuerdo con su modalidad de transferencia, pueden adoptar vehículos de conjugación o de transducción.

Por lo que hace referencia a las dianas objeto de la resistencia, cabe apuntar una triple modalidad ${ }^{5}$. En primer lugar, las modificaciones en los elementos estructurales de la bacteria, que engloban desde las proteínas de la pared o de la membrana externa hasta los elementos internos como ribosomas o ácido nucleico. En segundo lugar, existen las alteraciones en el «paso» o en el flujo, como son los cambios en la permeabilidad de las pori-

Tabla 1. Diferentes tipos de resistencia bacteriana a los antibióticos.

\footnotetext{
- Natural o intrínseca

- Adquirida

- Modificaciones en la información genética (mutaciones)

- Cromosómica

- Transferencia «extracromosómica» (plasmídica) - Transposones

- Integrones

- Pueden transferirse

- por conjugación

- por transducción (mediante fagos)
}

nas o los mecanismos de «captación-expulsióntransporte activo-acumulación». En tercer lugar, existen modelos de producción de enzimas supernumerarios que inactivan moléculas tales como las betalactamasas, los modificantes de aminoglucósidos o las ADN girasas. Desde el punto de vista aplicado al médico que prescribe, le interesa retener que la selección de cepas resistentes a los antimicrobianos obedece de modo esquemático a un hecho simple. La existencia de cepas bacterianas resistentes de baja prevalencia se incrementa de modo notable cuando se ejerce una exposición intensa a antimicrobianos ineficaces, con lo cual la prevalencia crece y las cepas resistentes se tornan predominantes.

\section{MÉTODOS DE DETECCIÓN}

El primer movimiento diagnóstico que se realiza de cara a documentar un determinado agente infeccioso obliga a realizar una adecuada toma de muestras. En el momento actual, la microbiología aplicada debe ofertar con claridad las posibilidades que, en el ámbito comunitario y hospitalario, existen en los diferentes sistemas sanitarios del país. Los gestores de recursos tratan de implantar una cultura basada en la eficiencia y en la agilidad de respuesta por parte del laboratorio ${ }^{6}$. Ello no es óbice para que el dermatólogo asistencial conozca que los métodos convencionales obligan a la siembra de muestras clínicas, al aislamiento de unidades formadoras de colonias y a la identificación de los microorganismos basada fundamentalmente en pruebas bioquímicas y nutricionales. En una segunda instancia, es posible realizar pruebas que determinan la sensibilidad a los antimicrobianos ${ }^{7}$. En nuestro ámbito, se siguen las recomendaciones internacionales (International Clinical Standard Laboratory, ICLS), europeas (European Committee on Antimicrobial Susceptibility Testing, EUCAST) y nacionales (Grupo Mensura). Conceptualmente, todas ellas distinguen entre métodos de cribado y de confirmación (tabla 2). Entre los primeros, cabe señalar aquellos que adoptan el modelo de microdilución en caldo y que informan 
Tabla 2. Métodos de detección de resistencias bacterianas.

CRIBADO

- Método de microdilución en caldo: CMI semicuantitativa. Valor variable.

- Método de difusión en disco: [antimicrobiano] (ug) y medición del diámetro del halo en $\mathrm{mm}$

CONFIRMACIÓN FENOTÍPICA

- Estudio de sinergia de doble disco

- Cuantificación de la CMI CONFIRMACIÓN GENOTÍPICA

- Hibridación con sondas de ADN

- Amplificación por PCR

- Secuenciación y detección de mutaciones

- Demostrar carácter cromosómico o plasmídico

ADN: ácido desoxirribonucleico. CMI: concentración mínima inhibitoria; PCR: reacción en cadena de la polimerasa.

de la concentración mínima inhibitoria (CMI) semicuantitativa, y los que adoptan el modelo de difusión en disco, que obligan a una medición de la inhibición del crecimiento asimilado al diámetro de un halo. Los métodos de confirmación pueden a su vez categorizarse en fenotípicos (estudio de sinergia en doble disco y cuantificación de la CMI) y genotípicos (hibridación con sondas de ADN, amplificación mediante reacción en cadena de la polimerasa, detección de mutaciones y secuenciación). Existen excelentes foros de difusión al respecto, que actualizan con un extremado rigor los aspectos de interés en la práctica asistencial.

\section{ESTADO ACTUAL}

Nuestro país se sitúa en el ámbito europeo entre aquellos cuya prevalencia de resistencias entre los microorganismos con significación clínica en pediatría frente a los antimicrobianos de mayor empleo es más elevada. Sin ánimo de ser exhaustivos, se acepta que, a lo largo de la primera década del siglo XXI, la prevalencia de resistencias de Streptococcus pneumoniae a la penicilina se situó en un $30 \%$, muy similar a lo documentado para la eri- tromicina. En el mismo período, la resistencias que muestran los aislados de Streptococcus pyogenes frente a macrólidos y lincosaminas alcanzan también el $25-30 \%$. En el mismo sentido cabe situar el hallazgo de una proporción notable de aislados que acumulan «corresistencia» y que vuelven a situar en proporciones de un tercio a las cepas que, siendo resistentes a una familia de antibióticos de empleo comunitario como son los betalactámicos, lo son también a otra familia de uso consolidado como los macrólidos.

Estos hechos se encuentran relacionados de manera inequívoca con el consumo de antimicrobianos. En el ámbito macrocomunitario, tal vez sea la aportación de Goosens et al. ${ }^{8}$ la que, a mediados de la década pasada, estableció de manera sólida la asociación entre aumento del consumo e incremento de las resistencias. En nuestro propio medio, hemos podido documentar este hecho en el marco de estudios descriptivos de corte transversal $^{9}$. Un aspecto adicional y no suficientemente valorado es la repercusión que el consumo de antibióticos ejerce sobre la microbiota bacteriana residente en un determinado ecosistema. La presión selectiva que ejerce un antimicrobiano sobre los microorganismos patógenos se extiende de manera fisiológica a los microorganismos autóctonos y por esa razón se asiste a la difusión de clonas resistentes en portadores sanos.

\section{POSIBILIDADES DE ACTUACIÓN}

Las posibilidades de actuación desde un marco de colaboración entre el dermatólogo y el microbiólogo pueden concretarse en cuatro. En primer lugar, cabe implementar la vigilancia del perfil de sensibilidad de los aislados con significación clínica y monitorizar el consumo de antimicrobianos $^{10}$. En este ámbito, el «European Antimicrobial Resistance Surveillance System» (EARSS) representa una red de redes que integra a una treintena de países de la Unión Europea, en la que vuelcan sus datos casi un millar de laboratorios y que da cobertura a más de cien millones de personas. Además de estar sometida a controles de calidad 
externos rigurosos, garantiza la recogida de datos de sensibilidad fiables y comparables, que permiten documentar las variaciones en la resistencia a antibióticos a lo largo del tiempo. De manera deliberadamente orientada desde el ámbito dermatológico, se pueden establecer las prioridades de información al servicio de buenas prácticas de prevención. Un aspecto adicional es el estudio desagregado del consumo de antibióticos por grupos etarios (en nuestro caso hasta los 18 años) por focalidades infecciosas y por áreas geográficas ${ }^{11}$. Nuestra experiencia en estudios multicéntricos a lo largo de la última década ha permitido documentar una gran variabilidad en la prescripción en diferentes segmentos etarios, en cuadros respiratorios evaluados a escala nacional ${ }^{12,13}$. Posee un gran interés diseñar estudios que aclaren la influencia de posibles determinantes, como la densidad de población o los índices de frecuentación de las consultas de atención primaria en la evolución de las resistencias bacterianas. En segundo lugar, entre las medidas que favorecen el control integral de las resistencias (tabla 3), cabe enumerar la eficiencia y adecuación de los métodos de detección de las mismas empleados por los servicios de microbiología, las medidas de prevención de infecciones comunitarias-nosocomiales por áreas sanitarias y los programas específicos sobre empleo de antibióticos. Estos últimos pueden con- llevar prácticas de uso restringido, de utilización cíclica o de minimización del impacto ecológico, en todo caso adaptados siempre a la realidad asistencial. Dentro de este apartado, deben considerarse las medidas educativas, tales como campañas dirigidas a la población general, contenidos incluidos en los diseños curriculares de los planes de formación de los adolescentes y jóvenes o de formación continuada del personal sanitario. Con esta finalidad, es plausible diseñar, por parte de los gestores sanitarios y de las direcciones de salud pública de las comunidades autónomas, módulos de aprendizaje o programas didácticos en los que pueden ser optimizados mediante el uso de las nuevas tecnologías. En tercer lugar, dentro de las estrategias claves para la prevención como el ya señalado modelo de los CDC, se establecen una docena de pasos ${ }^{2}$. En nuestro medio, parece oportuno destacar tres: adaptar el tratamiento al agente patógeno, consultar con expertos en enfermedades infecciosas y utilizar los datos «locales». La adaptación del tratamiento al agente etiológico se basa en la evidencia de que el empleo del antimicrobiano apropiado en términos de dosis, vía y duración salva vidas. Resulta determinante dirigir el tratamiento empírico hacia los agentes patógenos probables y de acuerdo con el antibiograma local, adaptando el definitivo a los microorganismos conocidos y a los resultados de las pruebas de sen-

Tabla 3. Diferentes medidas que favorecen el control integral de las resistencias a los antimicrobianos que pueden resultar útiles al dermatólogo clínico.

- Impulsar la correcta detección por el Servicio de Microbiología

- Establecer un plan de prevención de infecciones nosocomiales/comunitarias por «áreas» e implantar un programa eficiente de empleo de antibióticos

- Utilización «cíclica» : retirada-reintroducción

- Minimizar el impacto «ecológico»

- Adaptación a la REALIDAD ASISTENCIAL

- Medidas educativas:

- Campañas dirigidas a la población general

- Campañas en centros educativos

- Formación continuada de personal sanitario

- Ofrecer medios: Internet, módulos de aprendizaje didácticos, audiovisuales 
sibilidad. El apoyo de expertos en enfermedades infecciosas mejora la atención al paciente e integra aspectos determinantes que optimizan los recursos de la atención sanitaria. La fidelidad a los datos locales deriva del conocimiento de que la prevalencia de resistencias puede variar en el tiempo, con el lugar, con la población de pacientes y con la unidad en la que se les asiste. En última instancia, cabe incorporar opciones terapéuticas de uso apropiado, en las que las opciones de antimicrobianos elegibles sean valorados de acuerdo con la tendencia actual de la racionalización del uso de las mismas en términos de efectividad, utilidad y adecuación de costes ${ }^{14}$. De la conjunción y el equilibrio entre los análisis de las intervenciones sanitarias, tanto en términos de beneficio clínico como de evaluación económica ${ }^{15}$, depende nuestro éxito al controlar las resistencias bacterianas en la práctica dermatológica.

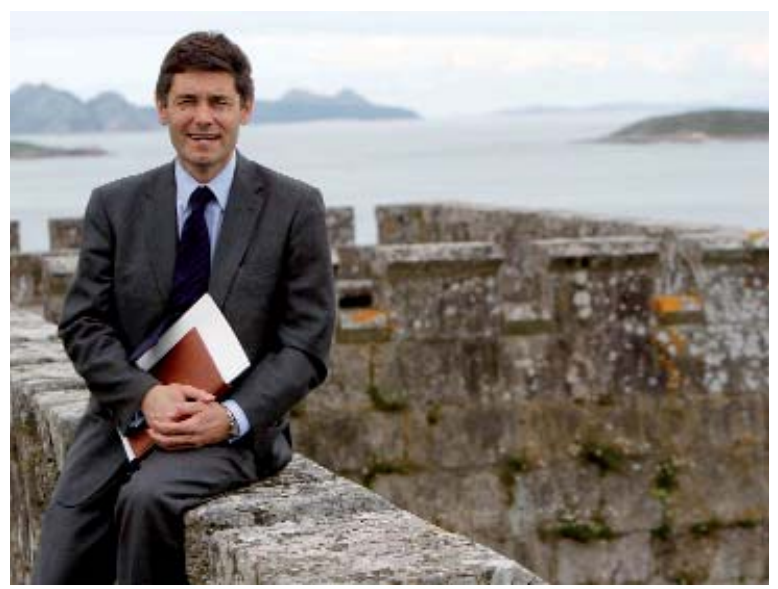

El doctor Eiros en las murallas del Monte Real de Bayona.

\section{BIBLIOGRAFÍA}

1. Nicolau DP. Current challenges in the management of the infected patient. Curr Opin Infect Dis. 2011;24 Suppl 1:S110.

2. http://www.cdc.gov/ncidod/dhqp/index.html [consultado el 10 de marzo de 2011].

3. Cornaglia G, Lönnroth A, Struelens M. Report from the European Conference on the Role of Research in Combating Antibiotic Resistance, 2003. Clin Microbiol Infect. 2004;10:47397.

4. Fernández L, Breidenstein EB, Hancock RE. Creeping baselines and adaptive resistance to antibiotics. Drug Resist Updat. 2011;14:1-21.

5. Eiros Bouza JM, Bachiller Luque MR, Clavo Nieves MD, Hernández Vázquez A. Temas actuales en el Laboratorio Clínico. Eiros JM, Valladolid: Ed. Mata Digital; 2010.

6. Eiros Bouza JM, Luquero Alcalde FJ. Sistemas de Información Microbiológica: Utilidad en la Vigilancia de las Enfermedades Infecciosas. Semergen. 2007;33:353-55.

7. Eiros Bouza JM, Martínez P, Ortiz de Lejarazu R. Procesamiento de muestras clínicas para el análisis microbiológico. Técnicas de Laboratorio. 1998;229:117-23.

8. Goossens H, Ferech M, Vander Stichele R, Elseviers M; ESAC Project Group. Outpatient antibiotic use in Europe and association with resistance: a cross-national database study. Lancet. 2005;365:579-87.

9. Pastor García E, Eiros Bouza JM, Mayo Iscar A, Bachiller MR. Consumo de antibióticos y resistencias bacterianas. Atención Primaria. 2005;35:167-8.

10. Pastor E, Eiros JM, Mayo A. Evolución del consumo de antibióticos en España. Medicina Clínica (Barc). 2003;120:78.

11. Pastor García E, Eiros Bouza JM, Mayo Iscar A, Bachiller R. Influence of population structure on the consumption of systemic antibiotics. Int J Antimicrob Agents. 2005;25:84-8.

12. Ochoa C, Eiros JM, Inglada L, Vallano A, Guerra L. Assessment of antibiotic prescription in acute respiratory infections in adults. J Infect. 2000;41:73-83.

13. Ochoa C, Inglada L, Eiros JM, Solis G, Vallano A, Guerra L; The Spanish Study Group on Antibiotics Treatments. The variability and appropriateness of antibiotic prescriptions in community-acquired acute respiratory infections in childhood. Pediatr Infect Dis J. 2001;20:751-58.

14. Eiros Bouza JM. Judicious use of antibiotics: a supporter challenge. Electronic J Biomed. 2007;1:5-7.

15. Eiros Bouza JM, Bachiller Luque MR. Farmacoeconomía: Criterios de calidad en Consumo y Prescripción de Antimicrobianos. Forhos. 2003;6:30-40. 